\title{
The Metadata Standards of Chinese Intangible Cultural Heritages*
}

\author{
YE Peng, ZHOU Yao-lin \\ School of information management, Wuhan University, Wuhan, China \\ Ye.peng@whu.edu.cn, Zhouyaolin@whu.edu.cn
}

\begin{abstract}
The paper analyzes the requirement of digital protection practices of Chinese intangible cultural heritages. The research bases on the comparative study about metadata standards and semantic analysis to put forward metadata standards of Chinese intangible cultural heritages. The paper also proposes the model and range of application by the metadata standards.

Index Terms - China, intangible cultural heritages, metadata standards
\end{abstract}

\section{Introduction}

According to the protection of the intangible cultural heritage convention by UNESCO, the intangible cultural heritages are wisdom of human civilization by oral traditions, performing arts, folk activities, manual skills and etc. They constitute the cultural space in the form of national culture all over the world. In recent years, traditional cultural ecology has been suffered varying degrees of damage with the rapid economic development. Many intangible cultural heritages are disappearing in China [1].

China is a large country. There are many types of intangible cultural heritages, which have many categories and system characteristics in this oriental county. So, the protection of Chinese intangible cultural heritages must proceed by the top-level design of government, which bases on the origin statistic and factor analysis about available resources. The current protections of intangible cultural heritages mainly lean to digital preservation and visual reconstruction technology in China. The research of digital conservation integrates text, images, audio and video, which base on the computer and database technology. But the semantic metadata research is rarely involved in digital intangible cultural heritages protection research in China.

Metadata standards are describing the data of the data. They mainly express data attributes and relationships. They also can create and store all information, such as position and history, of digital resources information for inquiring the file record [2].

The metadata technology is an important new tool to combine the digital information of intangible cultural heritages. It clearly defines the digital information content of quality, representation, data set, spatial reference, management style and other characteristics. It has been widely used in digital library, scientific research institution, government affairs office and some social institution in various fields. The metadata standards have become a research hotspot of intangible cultural heritages protection and digital archival science research in the world.

Hence, the scientific, perfect and practical intangible heritages metadata system will base on the reliable technology and mature method. The metadata standard of Chinese intangible cultural heritages should integrate the international mainstream metadata standards, and establish a metadata standards system. The set of system should include data standards, data contents and Chinese intangible cultural heritages application system of heterogeneous digital information. They can promote Chinese intangible cultural heritages protection, such as information storage, digital mining, file retrieval and multi-media distribution, in many field.

\section{II.The Importance of Chinese Intangible Cultural Heritage Metadata}

For digital library information management, almost every library, archives and museums all collect some art collections or cultural objects, which are difficult to be fully described in the standard library cataloging rules and vocabularies. The principles and methods of art catalog are not completely suit for system management and social application in the nowadays world. The international libraries, archives and museums usually tend to adopt metadata technology to describe their collections by computer system. The metadata standards of above organizations are according to digital collections information, which include attribute, elements, types and etc. The standards solve the problems about traditional library cataloging rules are hard to describe and define the collections of intangible cultural heritages. On the other hand, they also successful improve the cross-platform application for digital intangible cultural heritages protection.

Many sets of metadata standards have been widely used in many culture departments all over the world. They include traditional graphic standard such as CCO, LCSH, AAT etc., and also includes the digital information standard, such as CDWA/VRA Core metadata and DC metadata etc. [3]. In 2005, the national library of China had established a set of Metadata Standards, which include the general rule of metadata (D004), special metadata specification-the ancient literature and special specification (D006), special metadata

\footnotetext{
* A major program of key research base focused on the humanities and social science of Ministry of Education: Reach on the Construction and Service of Archival Information Resources based on Public Requirement (Grant No. 2009JJD870001)
} 
specification-electronic books (D005), special metadata specification-web and multimedia resources (D007), the principle of metadata (D012) for national library [4]. They are used to manage all kinds of digital resources, which include text, images, audio, video and other forms information. Nowadays, the metadata standards have become efficient and important tools to scientific protect and mine the digital information of cultural resources. Based on the characteristics of Chinese intangible cultural heritages projects, researchers had also built a framework of metadata standards.

\section{The Design Ideas of Chinese Intangible Cultural Heritages Metadata Standard}

\section{A. Taking the Experience of International Standards} With the development of the digital description technologies, there have been some Metadata Standards and models for all kinds of literature information resources. The Metadata Standards of intangible cultural heritages should be compatible with the international standard in China. It usually base on the demands of usability, generality and normativity for carrying on protection work of Chinese intangible cultural heritages.

By the analysis of the mainstream metadata standards, we can know the characteristics and requirements of Chinese intangible cultural heritages(Table I and Table II). Though above comparing, the metadata standards of Chinese intangible cultural heritages should establish on the DC metadata standards and absorb advantages of other metadata standards.

TABLE I A Comparative Analysis between The Mainstream Metadata Standard System in The World

\begin{tabular}{|c|c|c|c|c|}
\hline \multicolumn{2}{|r|}{ Element } & $\operatorname{ISAD}(\mathrm{G})$ & EAD & ISSAR \\
\hline \multirow{2}{*}{ Background } & $\begin{array}{c}\text { Editions released } \\
\text { time }\end{array}$ & The 1st in 1994; the 2nd in 2000 & the 1 st in $1998 ;$ the 2 nd in 2002 & the 1 st in 1996; the 2nd in 2004 \\
\hline & Main enabler & International Council on Archives & $\begin{array}{l}\text { The library of the university of California, } \\
\text { Berkeley }\end{array}$ & International Council on Archives \\
\hline \multirow[b]{2}{*}{$\begin{array}{l}\text { Demand } \\
\text { conditions }\end{array}$} & Main applicable object & Information of audio file & $\begin{array}{c}\text { Description files and manuscript } \\
\text { resources }\end{array}$ & Background of flie information \\
\hline & Aim & $\begin{array}{l}\text { Describe the electronic text and } \\
\text { content }\end{array}$ & Electronic full-text coding & Provides background information \\
\hline \multirow{3}{*}{ Elements } & Structure & 7 parts & 3 levels & 4 parts \\
\hline & elements & 6 & 2 & 4 \\
\hline & $\mathrm{DTD}^{2}$ & NA & Available & NA \\
\hline \multicolumn{2}{|r|}{ Superiority } & \multicolumn{2}{|c|}{ Easy to establish the database } & Easy to establish archival fond \\
\hline \multicolumn{2}{|r|}{ Weakness } & \multicolumn{2}{|l|}{ No Chinese version } & No network format \\
\hline
\end{tabular}

TABLE II A Comparative Analysis between The Mainstream Metadata Standard System in The World

\begin{tabular}{|c|c|c|c|c|}
\hline \multicolumn{2}{|r|}{ Element } & EAC & TEI & $\mathrm{DC}$ \\
\hline \multirow{2}{*}{ Background } & Editions released time & the 1 st in 2001 & the 1st in 1995 ; the 2 nd in 2002 & the 1st in 1999 \\
\hline & Main enabler & $\begin{array}{c}\text { University of Toronto; Yale } \\
\text { University }\end{array}$ & $\begin{array}{c}\text { International } \\
\text { Project:ACL/ALLC/ACH }\end{array}$ & America online computer library center \\
\hline \multirow{3}{*}{$\begin{array}{l}\text { Demand } \\
\text { conditions }\end{array}$} & Main applicable object & File background information & $\begin{array}{l}\text { Module transfer and conversion } \\
\text { module in file information }\end{array}$ & Digital files resources in network \\
\hline & Aim & $\begin{array}{c}\text { Provides background } \\
\text { information }\end{array}$ & $\begin{array}{l}\text { Electronic form of text coding } \\
\text { standard }\end{array}$ & $\begin{array}{l}\text { The application of electronic documents } \\
\text { interaction }\end{array}$ \\
\hline & Main application areas & The north America & The global & The global \\
\hline \multirow{3}{*}{ Elements } & Structure & 2 parts & 2 parts & 3 levels \\
\hline & elements & 2 & 4 & 15 \\
\hline & DTD & Available & Available & Available \\
\hline \multicolumn{2}{|r|}{ Superiority } & Easy to establish archival fonds & File could mix text and audio. & Unified using XML language \\
\hline \multicolumn{2}{|r|}{ Weakness } & No network format & Network support is poor & Details are poor \\
\hline
\end{tabular}

\section{B. Ensuring the Character of Original True}

The original true of intangible cultural heritages is a kind of real condition, which includes external environment, value subject and nature process without human intervention [6]. The invisible character of original true determines the intangible cultural heritages are close to people, society and

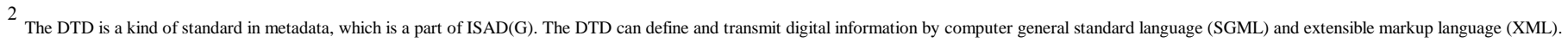


behaviour. It also decides the characteristics and value of it. The intangible cultural heritages have evolved and been changed with the social evolution of development. The artificial reforms should hurt the original true of intangible cultural heritages by people behaviours, which are bad for the normal life processes of intangible cultural heritages.

For these reasons, the Chinese intangible cultural heritages protection work needs establish a complete set of metadata standards, which base on the character of original true. The Chinese intangible cultural heritages metadata standards can effective determine and analysis the cultural value, endangered degree and interdependent characteristics. These elements are the basis of digital technology applying to the macro protection for Chinese intangible cultural heritages.

\section{Promoting the Combination of Technology and Cultural}

By 2020, the combination of technology and cultural will become a system for society and science research from "The outlines of Culture, science and technology innovation project" by Chinese government. The government plans to establish an innovative and intergraded model to promote cultural protections and industrial adjustments in China [7]. The research of intangible cultural heritages developments and protections are suit for Chinese government's main theme.

The metadata standards of intangible cultural heritages merge together traditional culture and modern technology as an applied solutions. They can help researchers to extend protection knowledge and deepen people's understanding of intangible cultural heritages. And they are also the important project sources and monitoring standards of intangible cultural heritages productive protection. The metadata standards are also the catalysts for digital intangible cultural heritages protection in China. On the one hand, the cultural heritages protection technology can protect and continue the precious intangible cultural heritages for using this technology. On the other hand, people can shape the forms for the modern social culture by the technology support and cultural promotion.

\section{IV.The Establishment for the Metadata Standards of Chinese Intangible Cultural Heritages}

The metadata standard can promote the properties and concepts for intangible cultural heritages, and establish an effective and accurate protection system for the public and society. At present, there is only one kind of general concepts in domestic ordinary metadata standards in China. The metadata standards have been used in Chinese libraries and museums. Some elements, such as name, category, subject and areas, are in these metadata standards. But just in general, the metadata standards are lack of specialized concepts of connotation and relationship for Chinese intangible cultural heritages.

So, the concepts of common entity can be selected and approached from general metadata standards. It makes the elements definition are generality and standardization for Chinese intangible cultural heritages protection [8]. Through above comparison and semantic analysis, we can get involved in attributes and concept of Chinese intangible cultural heritages.

From the operational guidelines for the implementation of the world heritages convention, the UNESCO official document has many identification standards to intangible cultural heritages. The important document is a useful operation tool to screen and login the human intangible representative list for many countries. In this document, there are 7 concepts in the $\mathrm{G}$ part. The concepts contain condition, reasons, supervision, description, management and influence factors [9].

The ministry of culture official declares the Chinese national level intangible cultural heritages representative list. The government also publicizes the format of declaration document, which is an important format instructor for protection work in China. From it, we can collect 9 element concepts, such as nation, history, pedigree, characteristics, values, equipment, basic content, endangered status and protective measures, to describe the Chinese intangible cultural heritages [10].

Base on the above semantic analysis and summary, the metadata standards of Chinese intangible cultural heritages should combine the type definition and comparison results of the international metadata standards. They establish on the DC standard metadata names [11] and DC standard metadata library [12], and also absorb the research achievements of Heaney, Michael (2000) [13] and the Powell, Andy (2007) [14]. The result of metadata standards of Chinese intangible cultural heritages contain 14 standard metadata names, 67 elements and expanding elements, and 67 field names(Table III).

\section{Conclusion}

The metadata standards of Chinese intangible heritages are the future trend of intangible cultural heritages protection and development. The research results and related applications also spread from archives and libraries to other cultural industry. The metadata standards of Chinese intangible heritages unify the digital information formats and mapping relation. They provide a great convenience and efficiency for heritage protection.

The metadata standards of Chinese intangible heritages can avoid compatibility problems from different hardware, different platforms and different formats of digital information resources. This approach lets us integrate the Chinese digital intangible cultural heritages resources, including isolated data and previously incompatible legacy systems. They also improve the efficiency and effect of Chinese intangible cultural heritages protection work.

For the metadata standards of Chinese intangible cultural heritages, there are also some problems should be solved. For example, the integration of standard Chinese system and international English system is an obstacle to metadata system. The problem led to a lot of retrieval and the application was unable to complete. So, it will be a further work needs to be discussed in the future. 
TABLE III The Set of Intangible Cultural Heritages Metadata Standards

\begin{tabular}{|c|c|c|}
\hline $\begin{array}{c}\text { Standard } \\
\text { metadata } \\
\text { name }\end{array}$ & $\begin{array}{c}\text { Elements and expanding } \\
\text { elements }\end{array}$ & Field name \\
\hline \multirow{3}{*}{ Title } & Title & DC_Title \\
\hline & Coordinate & DC_Title_Coordinate \\
\hline & Alternative & DC_Title_Alternative \\
\hline \multirow{3}{*}{ Creator } & Creator & DC_Creator \\
\hline & Main inheritance people & DC_Creator_Own \\
\hline & Other inheritance people & DC_Creator_Contributor \\
\hline -Contributor & Contributor & DC_Own \\
\hline \multirow{4}{*}{ Subject } & Subject & DC_Subject \\
\hline & Keyword & DC_Subject_Keyword \\
\hline & PlaceName & DC_Subject_PlaceName \\
\hline & Organization & DC_Subject_Organization \\
\hline \multirow{4}{*}{ Data } & Created Data & DC_Data_Created \\
\hline & Retention Period & DC_Data_RetentionPeriod \\
\hline & Secrecy Perid & DC_Data_SecrecyPerid \\
\hline & Custom Data elements & DC_Data_Custom \\
\hline \multirow{12}{*}{ Description } & Abstract & DC_Description_Abstract \\
\hline & Size & DC_Description_Size \\
\hline & Nation & DC Description_Nation \\
\hline & Features & DC_Description_Features \\
\hline & Value & DC_Description_Value \\
\hline & Endangered & DC_Description_Endangered \\
\hline & Content & DC_Description_Content \\
\hline & Reason & DC_Description_Reason \\
\hline & Influence elements & DC_Description_Influence \\
\hline & Article & DC_Description_Article \\
\hline & Annotation & DC_Description_Annotation \\
\hline & Custom Description & DC_Description_Custom \\
\hline Source & History & DC_Source_History \\
\hline \multirow{10}{*}{ Type } & Aggregation Level & DC_AggregationLevel \\
\hline & Text & DC_Type_Text \\
\hline & Image & DC_Type_StillImage \\
\hline & Sound & DC_Type_Sound \\
\hline & Vedio & DC_Type_MovingImage \\
\hline & Interactive Resource & DC_Type_InteractiveResource \\
\hline & Data Base & DC_Type_DataBase \\
\hline & Date Range & DC Type DateRange \\
\hline & Exception Date & DC_Type_DateException \\
\hline & Custom Type elements & DC_Type_Custom \\
\hline \multirow{6}{*}{ Format } & Record Type & DC_RecordType \\
\hline & Extnet & DC_Format_Extnet \\
\hline & Created Environment & DC_Format_CreatedEnvironment \\
\hline & Appled Environment & DC_Format_AppledEnvironment \\
\hline & Object Relational Mapping & DC_Format_ORM \\
\hline & Custom Format elements & DC_Format_Custom \\
\hline \multirow{5}{*}{ Coverage } & time range & DC_Coverage_Temporal \\
\hline & spatial dimension & DC_Coverage_Spatial \\
\hline & Officially range & DC_Coverage_Administration \\
\hline & Inheritance lineage & DC_Coverage_Pedigree \\
\hline & Custom Coverage elements & DC_Coverage_Custom \\
\hline \multirow{5}{*}{ Identifier } & Archival Code & DC_Identifier_ArchivalCode \\
\hline & ItemID & DC_Identifier_ItemID \\
\hline & Record Number & DC_Identifier_RecordNumber \\
\hline & Annotation & DC_Identifier_Annotation \\
\hline & Custom Identifier & DC_Identifier_Custom \\
\hline Language & Language & DC_Language \\
\hline \multirow{3}{*}{ Relation } & Related Archives & DC_RelatedArchives \\
\hline & Appendix & DC_Relation_Appendix \\
\hline & Custom Relation elements & DC_Relation_Custom \\
\hline \multirow{9}{*}{ Rights } & Access Right & DC_Right_AccessRight \\
\hline & Supervise & DC_Right_Supervise \\
\hline & Accrual Method & DC_Right_AccrualMethod \\
\hline & Accrual Periodicity & DC_Right_AccrualPeriodicity \\
\hline & Accrual Policy & DC_Right_AccrualPolicy \\
\hline & Audience & DC_Right_Audience \\
\hline & Intellectual Property & DC_Right_IntellectualProperty \\
\hline & Full Text Path & DC_Right_FullTextPath \\
\hline & Custom Right elements & DC_Right_Custom \\
\hline
\end{tabular}

\section{References}

[1] Long, X.-Q, "Connotation and Characters of Intangible Cultural Heritages and Its Protection", Journal of Hubei Institute for Nationalities (Philosophy and Social Sciences), 2006, pp47-52 (references)

[2] XIAO Long, "The general specification of national library metadata", Beijin: Beijing library press, 2011,pp.17 (references)

[3] M. Baca. "The Introduction of Metadata". Los Angeles: Getty Center, 2008, pp.71-72 (references)

[4] Electronic Publication: The national digital library project (National library of China) http://www.nlc.gov.cn/newstgc/gjsztsggc/bzgf/ (references)

[5] LI Bo, "The description and analysis of intangible cultural heritages information model", Journal of Sichuan institute of technology (Philosophy and Social Sciences), 2011, pp.120.

[6] Electronic Publication: A discuss of cultural heritages protection (YANG

Hao-zhong) http://www.snwh.gov.cn/feiwuzhi/lwzz/yxlz/200903/t20090327_69068. htm (references)

[7] Electronic Publication: The outlines of Culture, science and technology innovation project (Xinhua Net) http://news.xinhuanet.com/society/2012-05/17/c_111978516.htm (references)

[8] ZHAO Liang, "Metadata standard application frameworks and code", Shanghai: Shanghai science and technology literature press, 2005,pp. 45-46 (references)

[9] Electronic Publication: operational guidelines for the implementation of the world heritages convention (UNESCO) http://whc.unesco.org/en/guidelines (English)

[10] Electronic Publication: declaration template of Chinese national level intangible cultural heritages representative list- Ashimar (Chinese National Academy of Arts) http://www.ihchina.cn/inc/doc/asm.doc

[11] Electronic Publication: ISO 15836-2003 (International Organization for Standardization) http://www.niso.org/international/SC4/n515.pdf

[12] Electronic Publication: Dublin Core Collection Description Application Profile (Dublin Core Collection Description Working Group) http://www.ukoln.ac.uk/metadata/dcmi/collection-application-profile/

[13] Electronic Publication: An Analytical Model of Collections and their Catalogues (Heaney, Michael) http://www.ukoln.ac.uk/metadata/rslp/model/

[14] Electronic Publication: DCMI abstract model (Powell, Andy, Mikael Nilsson, Ambjörn Naeve, Pete Johnston) http://dublincore.org/documents/abstract-model 